\title{
Effects of resource availability on plant recruitment at the community level in a Mediterranean mountain ecosystem
}

\author{
Luis Matías ${ }^{\mathrm{a}, *}$, Lorena Gómez-Aparicio ${ }^{\mathrm{b}}$, Regino Zamora ${ }^{\mathrm{a}}$, Jorge Castro ${ }^{\mathrm{a}}$ \\ ${ }^{a}$ Grupo de Ecología Terrestre, Departamento de Ecología, Facultad de Ciencias, Universidad de Granada, 18071 Granada, Spain \\ ${ }^{\mathrm{b}}$ Instituto de Recursos Naturales y Agrobiología de Sevilla (CSIC), P.O. Box 1052, 41080 Sevilla, Spain
}

\begin{abstract}
A B S T R A C T
Coexisting plant species usually differ in resource requirements, which may also vary within species at successive demographic stages. Such differences become extremely important during the early life stages, since these are the most critical phases in woody-species recruitment, they depend heavily on resources, and they may determine future community composition. Under a global-change scenario, where climatic conditions, nutrient availability, and habitat characteristics are expected to be altered, it is difficult to predict the way in which plant recruitment will be affected. To understand the impact of different global-change drivers on community recruitment, we sowed a set of species representative of the different successional groups of a complete Mediterranean woody community under field conditions, and studied their emergence, growth, and survival along the main resource gradients of light, water, and nutrients. The light and nutrient gradients followed the natural range of conditions in the study area, but water availability was manipulated to simulate three contrasting climatic scenarios: wetter, drier, and current conditions. Structural equation modelling was used to provide a comprehensive analysis of the factors and relations governing plant recruitment. Overall, seedling emergence was determined directly by light; growth was determined by light and summer soil moisture; and survival was determined by summer soil moisture. Light was the main factor indirectly affecting the demographic stages of all species. However, the magnitude of the direct and indirect relationships varied among species. Particularly, species differed in their response to the expected drier climatic conditions, some (e.g. Pinus sylvestris, Acer opalus) being much more vulnerable than others (e.g. Cytisus scoparius, Salvia lavandulifolia). These differential responses could translate as major shifts in the structure of the overall plant community. Our results support the idea that the analysis of complex relations among essential resources is critical for accurate forecasts of the impact of climate change on community dynamics.
\end{abstract}

\section{Introduction}

Understanding plant foraging (sensu McNickle et al., 2009) is key to recognize plant relations with their immediate environment. Coexisting species usually differ in their tolerance to resource availability (Grubb, 1998; Schreeg et al., 2005), and these differences become even more critical when we consider species with different life forms (e.g. trees or shrubs) or from different successional stages (e.g. pioneers, mid-successional or late-successional). Specific resource requirements determine their relative abundance in the community, as well as the probability of success under the future climatic conditions predicted by forecasting models

\footnotetext{
* Corresponding author. Tel.: +34958 243 241; fax: +34958246166.

E-mail address: lmatias@ugr.es (L. Matías).
}

(Houghton et al., 2001). Therefore, community approaches moving beyond the study of particular species are crucial to increase our ability to predict changes in community dynamics along abiotic gradients, and to determine the precise relevance of these gradients as drivers of community dynamics.

Seedling establishment is the most sensitive and critical stage for woody-species recruitment (Houle, 1994; Hampe and Arroyo, 2002; Castro et al., 2005; Mendoza et al., 2009a). Early life stages depend heavily on specific environmental conditions and resources, mainly light, water, and nutrients (Harper, 1977; Kitajima and Fenner, 2000; Gômez-Aparicio et al., 2008). Resource availability is subject to high spatial and temporal heterogeneity (Maestre et al., 2003; Quero et al., 2011), and is expected to be even more heterogeneous under a global-change scenario (Houghton et al., 2001). Conditions predicted by global-change forecasting models for the coming decades may entail shifts in the availabil- 
Table 1

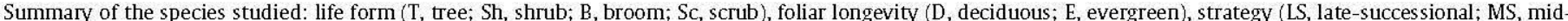

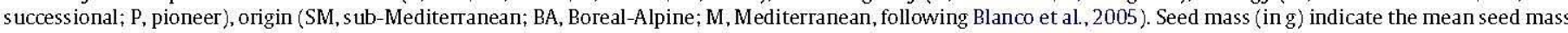

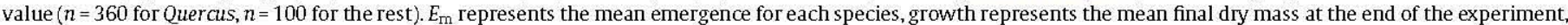
and Surv represents the mean survival.

\begin{tabular}{|c|c|c|c|c|c|c|c|c|}
\hline Species & Family & Life form & Foliar longevity & Strategy & Seed mass & $E_{\mathrm{m}}(\%)$ & Growth $(g)$ & Surv (\%) \\
\hline Acer opaius & Aceraceae & $\mathrm{T}$ & $\mathrm{D}$ & LS & 0.046 & 9.2 & 0.16 & 34.8 \\
\hline Pinus sylvestris & Pinaceae & $\mathrm{T}$ & $\mathrm{E}$ & LS & 0.012 & 25.4 & 0.19 & 9.4 \\
\hline Sorbus aria & Rosaceae & $\mathrm{T}$ & $\mathrm{D}$ & LS & 0.036 & 37.5 & 0.45 & 53.4 \\
\hline Quercus ilex & Fagaceae & $\mathrm{T}$ & $\mathrm{E}$ & LS & 4.480 & 86.1 & 2.00 & 87.6 \\
\hline Crataegus monogyna & Rosaceae & Sh & $\mathrm{D}$ & MS & 0.079 & 32.5 & 0.11 & 52.4 \\
\hline Berberis hispanica & Berberidaceae & Sh & D & MS & 0.018 & 24.5 & 0.06 & 56.1 \\
\hline Cytisus scoparius & Fabaceae & $\mathrm{B}$ & $\mathrm{E}$ & $\mathrm{P}$ & 0.011 & 44.7 & 0.99 & 70.3 \\
\hline Salvia lavandulifolia & Lamiaceae & $\mathrm{Sc}$ & $\mathrm{E}$ & $\mathrm{P}$ & 0.005 & 8.1 & 2.26 & 71.6 \\
\hline
\end{tabular}

ity of basic resources due to changes in the precipitation patterns (Giorgi and Lionello, 2008), habitat structure (Peñuelas and Boada, 2003), and nutrient cycles (Jonasson et al., 1999; Jensen et al., 2003; Sardans and Peñuelas, 2007), thus altering their role in plant regeneration. Consequently, a complete overview of the way in which different coexisting species during early life stages respond to gradients of resource availability is crucial for accurately assessing the regeneration capability of the different species of the community under global change.

Regeneration ability is determined by several co-occurring and interacting factors, exerting their effects in direct as well as indirect ways (Escudero et al., 2000; Garrido et al., 2005; GarcíaCamacho et al., 2010). A mechanistic model seeking to identify a causal response can be found only by an analytical tool capable of including not only several factors and their interactions, but also their direct and indirect effects. The complex relationships among resources and early recruitment in plants could be explored in an integrated way by the use of structural equation modelling (SEM). SEM is a statistical method that helps provide insights into complex theoretical issues. These techniques are typically used to confirm or disprove an a priori hypothesised model, i.e. to test the statistical adequacy of a proposed causal model (Browne, 1982; Hayduck, 1987; Shipley, 2000; Iriondo et al., 2003). Situations observed when analysing the processes that affect community recruitment (seedling emergence, growth, and survival) can be expressed in the form of a hypothesis that incorporates all the variables that are presumed to be relevant according to existing knowledge (Iriondo et al., 2003), providing an overall view of the factors and relations directly and indirectly affecting plant recruitment.

The objective of this work was to determine the effect and the relative importance of abiotic conditions on the recruitment probabilities of a woody community from a Mediterranean mountain under a global-change scenario. For this, we sowed seeds from eight tree and shrubby species representative of the different successional stages of the community under field conditions, and studied their emergence, growth, and survival along a light, water, and nutrient gradient. The light and nutrient gradient followed the natural range of conditions in the study area, but natural levels of water availability were altered by adding or excluding water during summer to simulate three contrasting climatic scenarios: milder, drier, and current conditions. Previous studies have analysed the response of a few species (Laskurain et al., 2004; Gômez-Aparicio et al., 2008) or demographic stages (Jordano and Herrera, 1995; Escudero et al., 2000; Garrido et al., 2005) at different resource levels (Carson and Pickett, 1990; Stevens et al., 2006). However, this is the first study available that experimentally analyses the way in which abiotic-resource availability, both current and predicted, influences Mediterranean woody-species recruitment and relationships among the different demographic stages at a community level (but see Luzuriaga and Escudero, 2008 for a herbaceous community). Specifically, we used SEM in order to answer the following questions: (1) What are the main resources affecting seedling recruitment both direct and indirectly? (2) How do the sign and the magnitude of the effects vary among demographic stages? (3) Do resources affect all species and functional groups of the community in a similar way? (4) What are the projections for the recruitment of the different species of the community under contrasting scenarios? Answers to these questions would provide us a better understanding of recruitment dynamics and enable us to predict their consequences for future forest composition under a global-change scenario.

\section{Materials and methods}

\section{Study area and species}

The experiment was conducted in La Cortijuela area, within the limits of Sierra Nevada National Park $\left(37^{\circ} 05^{\prime} \mathrm{N}, 3^{\circ} 28^{\prime} \mathrm{W}\right.$, Granada, SE Spain), with a mean elevation of $1650 \mathrm{~m}$ a.s.l. This mountain area has a continental Mediterranean climate, with cold winters and hot, dry summers. Rainfall is $811 \mathrm{~mm} \mathrm{yr}^{-1}$, mostly during spring and autumn (means 1990-2008). The experiment was conducted inside a natural 12.4-ha fenced area since 1986 , with areas covered by trees, shrubs, and open areas without woody cover. For the study species, we selected eight target species representative of the three main successional stages on Mediterranean mountains: four trees, of which two were deciduous (Sorbus aria L. and Acer opalus Mill.) and two were evergreen (Pinus sylvestris L. and Quercus ilex L.); two mid-successional shrubs (Berberis hispanica L. and Crataegus monogyna Jacq.); and two pioneer shrubs: (Cytisus scoparius L. and Salvia lavandulifolia Vahl.). All are native to the study area and widely distributed throughout Mediterranean mountains, but P. sylvestris populations in Sierra Nevada are at the species' southernmost range limit (Castro et al., 2004). Further details on species characteristics can be found in Table 1 .

\section{Experimental design}

To test the effect of different abiotic factors on woody recruitment, we sowed the eight species under different conditions of light, water, and nutrients. To do this, we selected three different habitats where seedling emergence naturally occurs (Castro et al., 2005; Mendoza et al., 2009a), covering most of the natural gradient of light availability in Mediterranean areas: open areas, under the shrub canopy, and under the tree canopy. The natural levels of water availability were regulated by experimentally adding or reducing water input with respect to the control plots to simulate wetter or drier summers, as well as current climatic conditions. Mild summers were simulated on $2 \mathrm{~m} \times 2 \mathrm{~m}$ experimental plots with an irrigation system composed of four sprinklers with 
$90^{\circ}$ angle and $2 \mathrm{~m}$ range located at the corners. Each week from mid-June to the end of September, we added a water quantity of $121 \mathrm{~m}^{-2}$, simulating a summer storm. The total water added during summer was $1801 \mathrm{~m}^{-2}$, equivalent to the mean summer rainfall of the five milder summers of the 1902-2006 series in the study area (Matías et al., 2011). Drier summers were simulated on $2 \mathrm{~m} \times 2 \mathrm{~m}$ experimental plots with a rainout shelter following the main design by Yahdjian and Sala (2002), intercepting some 35\% of the rainfall from April to September, simulating longer and drier summers as predicted by SRES-A2 scenario from IPCC (IPCC, 2007). Additional $2 \mathrm{~m} \times 2 \mathrm{~m}$ experimental plots were placed with no water manipulations as control of the current climatic conditions.

A total of 72 plots were placed across the 3 habitat types ( 24 under each type), randomly assigning 8 of them to each of the habitat and climatic combinations ( 3 habitats $\times 3$ climatic scenarios $\times 8$ replicates). In each plot, the 8 study species were sown. The number of seeds sown differed in each species, ranging from 5 to 15 , depending on seed mass and germination rates, checked in a previous experiment in the same study area (Mendoza et al., 2009b) to reach a similar seedling density for the different species. The sowing was performed in December 2006, and seeds stayed in the soil throughout the winter, undergoing a natural cold-stratification period in the field, which increased germination rates (GarcíaFayos et al., 2001). Emergence was recorded in spring 2007, noting the proportion of seedlings that emerged from the number of seeds sown per plot. Survival was monitored after two complete growing seasons, in September 2008. The proportion of surviving seedlings in September 2008 from the number that had emerged in spring 2007 in each plot was used as a survival indicator. Once the experiment had finished, all surviving seedlings were harvested. The whole plants were removed by excavating the whole root system with a pneumatic hammer. Roots were carefully washed to remove soil remains. Then, plants were oven dried at $70^{\circ} \mathrm{C}$ for at least $72 \mathrm{~h}$, and weighed for total biomass. Mean biomass of seedlings growing in the same plot was used as indicator of total growth during the experiment.

\section{Abiotic environmental characterization}

Three principal indicators of abiotic environment were selected: light, water, and nutrient availabilities. All these variables were measured in the 72 experimental plots. Light availability was measured by hemispherical photography (Valladares and Guzmán, 2006). Photographs were taken at ground level using a horizontally levelled digital camera (CoolPix 5000, Nikon, Tokyo, Japan) and aimed at the zenith, using a fish-eye lens of $180^{\circ}$ field of view(FCE8, Nikon). The images were analysed using Hemiview canopy analysis software ver. 2.1 (1999, delta-T Devices, Cambridge, UK), estimating the parameters known as direct and indirect site factor (DSF and ISF respectively, Rich 1990). Both parameters were combined into a global site factor (GSF), which integrates the total amount of light over the whole year, ranging from 0 (light absence) to 1 (100\% light availability). Soil-water content was measured monthly during growing seasons (May toSeptember) in all plots by the timedomain reflectometry method (TDR-100, Spectrum Technologies Inc., USA) integrating the values from the uppermost $20 \mathrm{~cm}$ of soil. Study plots were sampled by two perpendicular transects, recording the volumetric water content every $0.5 \mathrm{~m}$. From these data, we used two variables: soil moisture at emergence (moist spring) as the mean volumetric water content in May; and soil moisture during the growing period (moist summer) as the mean volumetric water content from June to September.

Soil-nutrient availability was analysed for the most important resources: nitrogen $(\mathrm{N})$ and phosphorus $(\mathrm{P})$. In the same plots where seedlings were growing, samples were taken from the upper soil layer $(0-8 \mathrm{~cm})$ in May and August of 2007 and 2008, coinciding with the periods of highest biological soil activity and severest drought, respectively. Also, 15 and $7.5 \mathrm{~g}$ of soil samples were extracted for $1 \mathrm{~h}$ in agitation with $75 \mathrm{ml}$ of $0.5 \mathrm{M} \mathrm{K}_{2} \mathrm{SO}_{4}$ and $0.5 \mathrm{M}$ $\mathrm{NaHCO}_{3}$, respectively, and filtered through Whatman GF-D filters. From $\mathrm{K}_{2} \mathrm{SO}_{4}$ extracts, we determined dissolved organic $\mathrm{N}$ (DON) with a Shimadzu TOC-V CSH analyser. Inorganic P was determined in $\mathrm{NaHCO}_{3}$ extracts by the Olsen method (Watanabe and Olsen, 1965). Mean values of DON and inorganic P per plot among years and seasons were used as indicators of $\mathrm{N}$ and $\mathrm{P}$ availability, respectively. Additional methodological details can be found in Matías et al. (2011).

\section{Data analysis}

SEM was used to test the relevance of different abiotic factors on emergence, growth, and survival of woody seedlings (Browne, 1982; Hayduck, 1987; Shipley, 2000). As the sample size is relatively small ( 70 data in the best case), we followed the recommendations of Tanaka (1987) when designing the model to test. Thus, the number of variables used was limited as much as possible. Our working model proposed that the recruitment probability of each seedling is the result of the probabilities of success in three consecutive processes: seedling emergence, seedling growth, and seedling summer survival (Jordano and Herrera, 1995). We hypothesised that these processes are controlled by resource availability: light, water, and nutrients, although each in a different way (Fig. 1). Emergence is affected mainly by light conditions and by soil moisture in spring. Growth depends on light and spring soil moisture, too, but also on summer soil moisture as well as nutrient availability. Finally, survival is controlled by light, summer soil moisture, and nutrient availability. Furthermore, successive processes may affect each other; hence, growth is affected by emergence, and survival by emergence and growth. Because soil-moisture availability is highly dependent on irradiance, we also included the effect of light on spring and summer soil moisture. Additionally, the correlations among abiotic variables were included in the model: moist spring and moist summer, $\mathrm{N}$ and $\mathrm{P}$, light and $\mathrm{N}$, and light and $\mathrm{P}$. The model was calculated separately for the different species studied. Due to high mortality in $P$. sylvestris during the experiment, growth and related variables were excluded from the model for this species. Given that the seedling density at emergence (mean value per plot of 7.4 seedlings $/ \mathrm{m}^{-2}$ ) and at the end of the experiment $\left(4.5\right.$ seedlings $/ \mathrm{m}^{-2}$ ) was relatively low, and since we detected no previous effect of seedling density on growth or survival, we decided not to include any possible effect of competition in our model. The relationships included in our model come from a priori knowledge, based on other studies in the same area and with the same plant community (Castro et al., 2005; Gómez-Aparicio et al., 2008; Quero et al., 2008; Mendoza et al., 2009a,b).

All variables were assessed for normality prior to statistical analyses. Suitable transformations (log, arcsin) were performed when necessary to improve normality according to Zar (1984). The maximum-likelihood method was used to estimate the standardized path coefficients in our model (Shipley, 2000). The degree of fit between the covariance in the observed data with that expected if the working model is true was first examined by a goodness-of-fit $\chi^{2}$. Non-significant $\chi^{2}$ indicates that the pattern of covariance predicted by the hypothesis is no different from the observed data, and thus the model could be accepted (Iriondo et al., 2003). However, it is generally accepted that the $\chi^{2}$ test should be interpreted with caution and supplemented with other goodness-of-fit indices (Bollen, 1989; Lohelin, 1992). Therefore, the Bentler-Bonnet Normed Fit Index (NFI) was used, as it gives a measure of the practical fit of the model while ignoring the number of 


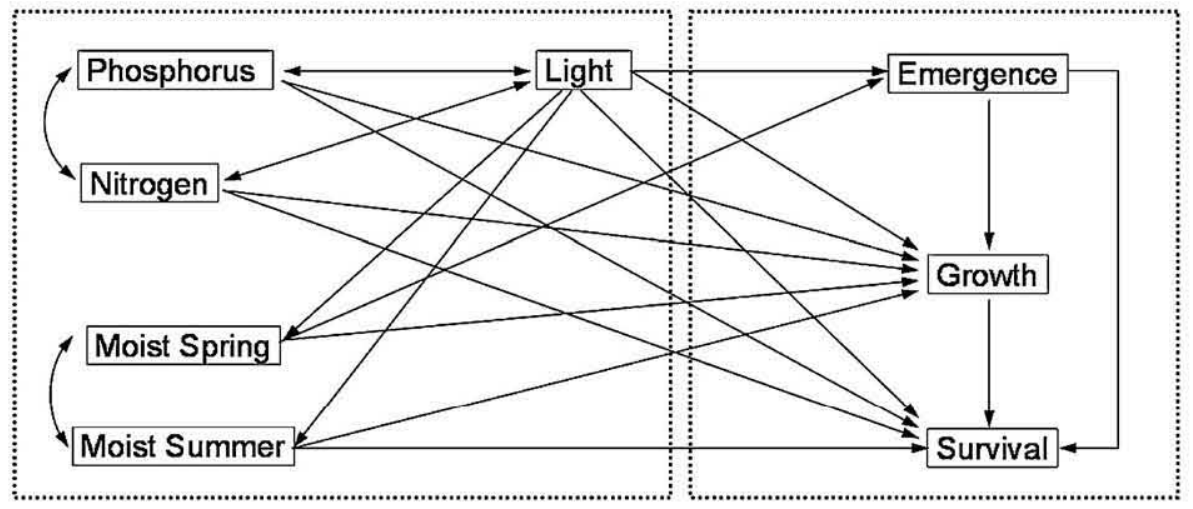

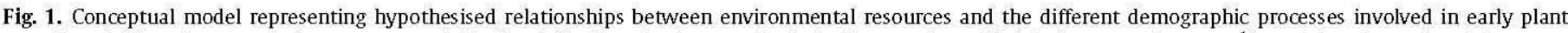

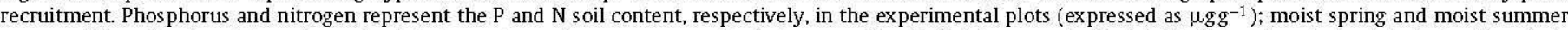

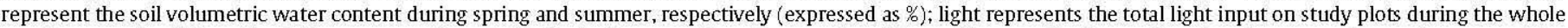

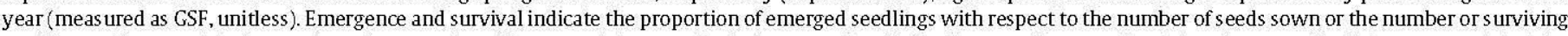

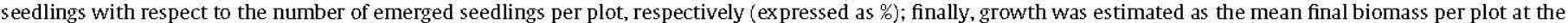
end of the experiment (expressed ing).

subjects (Bentler and Bonnet, 1980; Mitchell, 1992; Escudero et al., 2000). Tanaka (1987) also recommended the simultaneous use of the Goodness-of-Fit Index (GFI) because it is not affected by the estimation methods (Tanaka and Huba, 1985). NFI and GFI ranged from 0 to 1 , and values $>0.9$ indicate a good fit of the model to the data (Tanaka, 1987; Mulaik et al., 1989). Analyses were conducted using AMOS 5.0 (Arbuckle, 1994).

\section{Results}

Our experiment covered a wide range of the abiotic conditions that affected seedling emergence, growth, and survival (Table 2). The SEM provided a good overall fit for all species and functional groups (Fig. 2). The 8 path models presented an excellent fit with the observed data, as indicated by their non-significant $\chi^{2}$ $(\boldsymbol{P}>0.05)$, and by goodness-of-fit indices (NFI and GFI $>0.9$ in all cases). Squared multiple-correlation estimates for emergence were generally low, ranging from 0.09 for $S$. lavandulifolia to 0.45 for $S$. aria (Fig. 2). Overall, growth was the best-fitted demographic stage, with squared multiple-correlation estimates from 0.27 in the case of $A$. opalus to 0.60 for $S$. lavandulifolia. Finally, survival squared multiple-correlation estimates varied from 0.09 in the case of $C$. scoparius to 0.60 for A. opalus.

Seedling emergence was directly affected by light availability and spring soil moisture (Table 3 ). Light availability negatively affected the emergence of all species but Q. ilex and S. lavandulifolia. Spring soil moisture negatively affected emergence of $Q$. ilex but positively affected that of A. opalus (Fig. 2A and B). Seedling growth was determined mainly by light availability and summer soil moisture, although other factors such as spring soil moisture or soil nutrients also affected the growth of some species or groups (Fig. 2). Light availability and summer soil moisture positively influenced growth in all species. Spring soil moisture negatively decreased the growth of B. hispanica and S. lavandulifolia (Fig. 2E and H), and P availability increased $S$. aria growth, whereas $\mathrm{N}$ slowed the growth of both pioneer species C. scoparius and S. lavandulifolia. Finally, seedling survival of all species except pioneers was determined primarily by summer soil moisture, consistently with a positive effect. Light availability proved negative for both mid-successional shrubby species ( $B$. hispanica and $C$. monogyna). Light was the main resource indirectly affecting emergence and especially survival, the influence being strong enough in some cases to change the sign of direct effect (Table 3). The largest indirect effect of light occurred for the emergence of $Q$. ilex and A. opalus, and for survival of most species. The positive indirect effect of summer soil moisture on $A$. opalus survival reinforced its positive direct effect.

Successive processes involved in recruitment were related in some cases. A positive effect of growth on survival was detected for mid-successional shrubs ( $B$. hispanica and $C$. monogyna), as well as a negative effect of emergence on survival for $A$. opalus and $S$. lavandulifolia, this effect being positive for $S$. aria. Among abiotic variables, light negatively affected soil moisture, especially during spring, but also in summer for Q ilex and pioneer shrubs. Correlations among abiotic variables were positive in all cases: moist spring and moist summer, $\mathrm{N}$ and $\mathrm{P}$, light and $\mathrm{N}$, and light and $\mathrm{P}$.

\section{Discussion}

SEM enabled us to analyse the complex relationships among abiotic resources and the early demographic stages that determine plant recruitment. The relative importance of the abiotic factors varied strongly among demographic stages. That is, emergence was determined mainly by a direct light effect; growth by a combination of direct effects of light, summer soil moisture and, in some cases, nutrients; and survival by a direct effect of summer water availability and an indirect light effect. Moreover, there were marked differences in the intensity of the effects among species, which may have significant consequences for the recruitment pattern of the community. These consequences may become even stronger under a global-change scenario, where the resource-availability pattern is expected to be altered.

\section{Seedling emergence}

At emergence, light was the main direct factor affecting most species, invariably in a negative way. Higher emergence in lowlight plots with dense plant cover is common in dry areas such as the Mediterranean (Rey and Alcántara, 2000; Gômez, 2004; Jurado et al., 2006; Mendoza et al., 2009b), and is presumably related to buffered and constant temperatures and soil moisture. However, this relation was non-significant for $Q$. ilex and S. lavandulifolia. The larger mass of $Q$, ilex acorns probably confer them some independence from abiotic conditions during emergence (Quero et al. 2007), whereas in the case of S. lavandulifolia, the lack of a light effect on emergence could be a characteristic of its pioneer status, allowing the emergence under a wide gradient of light conditions 
(A) Quercus ilex

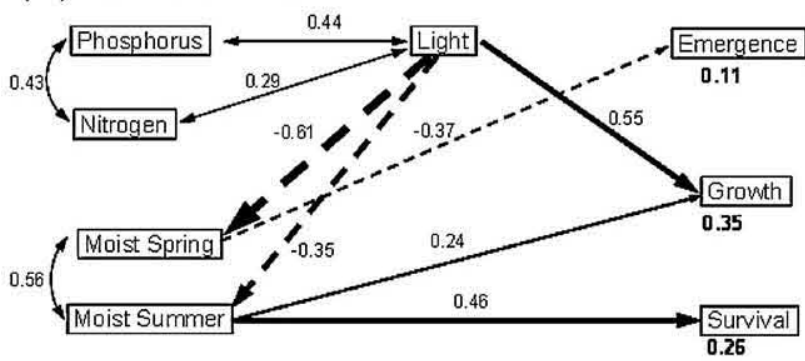

$\mathrm{NFI}=0.97 ; \mathrm{GFI}=0.99 ; \chi^{2}=4.08 ; P=0.85 ; N=70$

(C) Pinus sylvestris

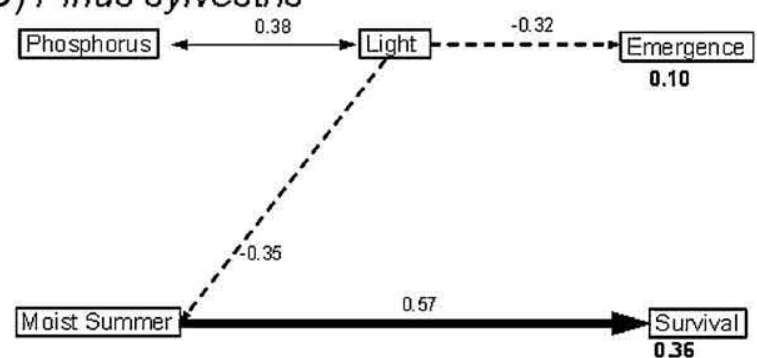

$\mathrm{NFI}=0.94 ; \mathrm{GFI}=0.98 ; \chi^{2}=3.21 ; P=0.36 ; N=56$

(E) B. vulgaris

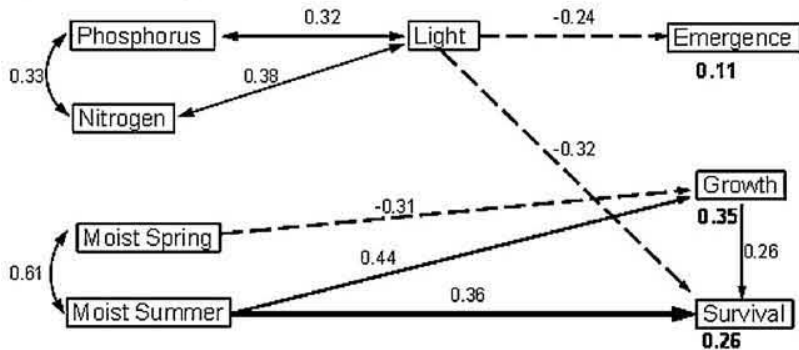

$\mathrm{NFI}=0.89 ; \mathrm{GFI}=0.95 ; \chi^{2}=10.53 ; P=0.23 ; N=44$

(G) C. scoparius

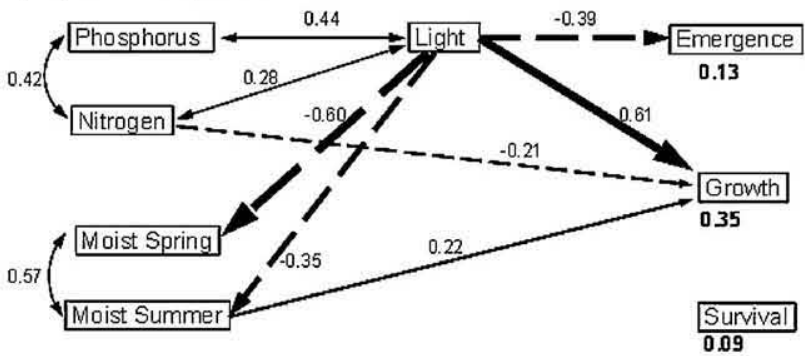

$\mathrm{NFI}=0.91 ; \mathrm{GFI}=0.95 ; \chi^{2}=13.05 ; P=0.11 ; N=68$

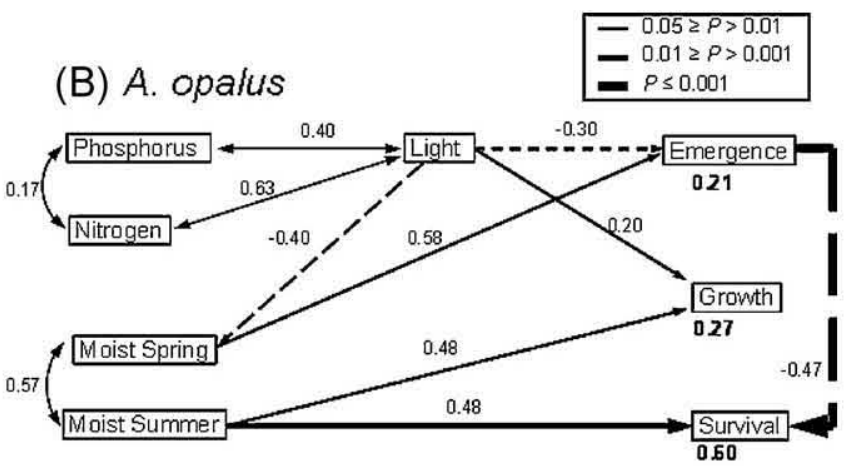

$\mathrm{NFI}=0.90 ; \mathrm{GFI}=0.91 ; \chi^{2}=10.05 ; P=0.12 ; N=22$

(D) S. aria

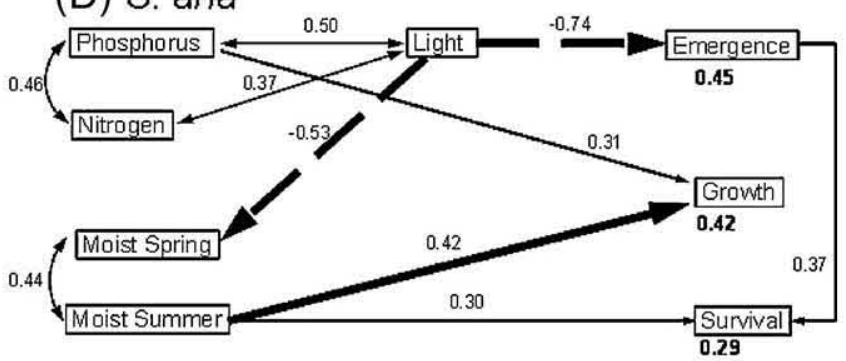

$\mathrm{NFI}=0.95 ; \mathrm{GFI}=0.96 ; \chi^{2}=6.79 ; P=0.45 ; N=46$

(F) C. monogyna

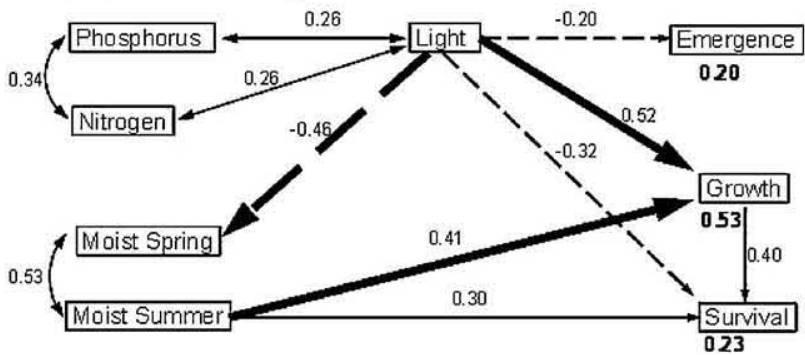

$\mathrm{NFI}=0.92 ; \mathrm{GFI}=0.96 ; \chi^{2}=9.23 ; P=0.24 ; N=51$

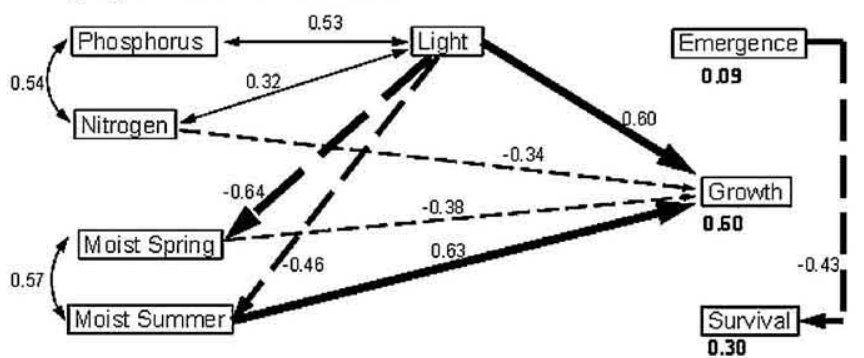

$\mathrm{NFI}=0.95 ; \mathrm{GFI}=0.96 ; \chi^{2}=5.30 ; P=0.62 ; N=33$

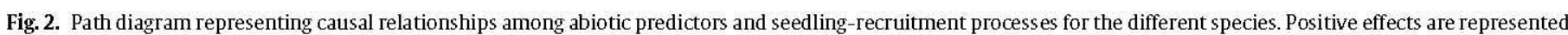

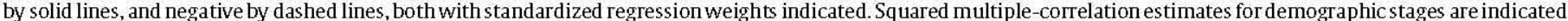

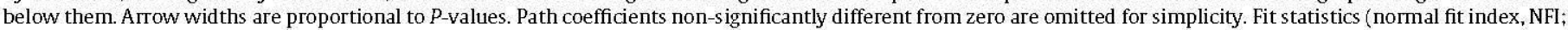
goodness of fit index, GFI; $\chi^{2} ; P$-value) and sample size $(N)$ are given at the bottom of each path. 
Table 2

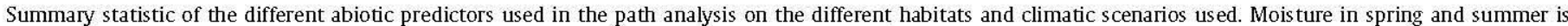

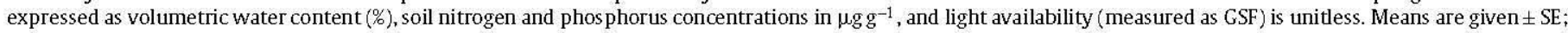
$N=8$ per treatment combination.

\begin{tabular}{|c|c|c|c|c|c|}
\hline & Light & Moist spring & Moist summer & Phosphorus & Nitrogen \\
\hline \multicolumn{6}{|l|}{ Open } \\
\hline Dry & $0.86 \pm 0.01$ & $18.00 \pm 0.33$ & $5.38 \pm 0.13$ & $3.15 \pm 0.15$ & $4.18 \pm 0.37$ \\
\hline Control & $0.88 \pm 0.01$ & $21.33 \pm 0.83$ & $6.03 \pm 0.16$ & $4.04 \pm 0.44$ & $4.64 \pm 0.26$ \\
\hline Wet & $0.88 \pm 0.01$ & $21.14 \pm 0.61$ & $9.99 \pm 0.22$ & $4.58 \pm 1.08$ & $4.57 \pm 0.32$ \\
\hline \multicolumn{6}{|l|}{ Shrubland } \\
\hline Dгу & $0.42 \pm 0.04$ & $22.37 \pm 0.91$ & $7.18 \pm 0.14$ & $2.27 \pm 0.17$ & $4.91 \pm 0.56$ \\
\hline Control & $0.44 \pm 0.04$ & $26.02 \pm 0.84$ & $8.31 \pm 0.11$ & $2.47 \pm 0.21$ & $4.62 \pm 0.45$ \\
\hline Wet & $0.41 \pm 0.04$ & $25.87 \pm 0.59$ & $11.99 \pm 0.20$ & $2.63 \pm 0.33$ & $4.74 \pm 0.66$ \\
\hline \multicolumn{6}{|l|}{ Forest } \\
\hline Dry & $0.19 \pm 0.02$ & $23.14 \pm 0.30$ & $7.29 \pm 0.12$ & $2.57 \pm 0.25$ & $4.30 \pm 0.24$ \\
\hline Control & $0.25 \pm 0.01$ & $26.34 \pm 0.86$ & $8.32 \pm 0.17$ & $2.84 \pm 0.26$ & $3.53 \pm 0.15$ \\
\hline Wet & $0.23 \pm 0.02$ & $26.91 \pm 0.75$ & $12.27 \pm 0.23$ & $2.50 \pm 0.19$ & $3.27 \pm 0.27$ \\
\hline Mean & $0.51 \pm 0.03$ & $23.46 \pm 0.41$ & $8.53 \pm 0.28$ & $3.01 \pm 0.16$ & $4.31 \pm 0.14$ \\
\hline Range & $0.10-0.91$ & $16.70-31.65$ & $4.91-13.59$ & $1.57-11.69$ & $2.52-7.30$ \\
\hline
\end{tabular}

(Gaudio et al., 2008). Spring soil moisture determined emergence for $Q$. ilex and $A$. opalus, although with contrasting patterns. There was a negative effect in the case of $Q$. ilex, supporting the contention that excess soil moisture may limit germination in this species (see Pêrez-Ramos and Marañôn, 2009 for other Quercus species). Spring soil moisture had a positive effect on the germination of $A$. opalus, a deciduous tree, suggesting that the high water requirements of this species (Gômez-Aparicio et al., 2006; Quero et al., 2008; Mendoza et al., 2009b) may be expressed even during this early life stage.

\section{Seedling growth}

Light and summer soil moisture were the main factors directly influencing seedling growth across species, although the magnitude of its effect varied among them, being pioneer shrubs $(C$. scoparius and S. lavandulifolia) the group with the strongest light dependence. Pioneer species present characteristics such as variable photosynthetic rate or optimised foliar architecture that allow them to maximize growth under high light availability and to protect themselves from excess radiation (Valladares and Pearcy, 1998; Valladares, 2000). By contrast, deciduous trees ( $A$. opalus and $S$. aria) have the capacity to grow under low irradiance below tree canopies (Bazzaz and Picket, 1980; Emborg, 1998; Flores and Jurado, 2003), but these trees are less able to take advantage of higher light intensities (Kitajima, 1994; Valladares and Pearcy, 1997).

The positive relationship of summer soil moisture and seedling growth was consistent across species. All species gained higher biomass (both aboveground and belowground) under wetter conditions (Matías et al., unpublished data), thus allowing seedlings to increase carbon acquisition and to explore a higher volume of soil for water and nutrients in successive growing seasons (Canadell and Zedler, 1995; Lloret et al., 1999). The effect of nutrients on seedling growth was not as generalized as that of light or water, but they also influenced the growth of some species. Thus, P availability enhanced growth in $S$. aria, whereas a negative causal relationship was found between $\mathrm{N}$ levels and growth for both pioneer shrubs. $\mathrm{P}$ has been identified as one of the most limiting nutrients in Mediterranean ecosystems (Sardans et al., 2004) but, at least at this early life stage, only $S$. aria in the present study was growth-limited by $\mathrm{P}$. The negative effect of $\mathrm{N}$ on the growth of pioneer species could be explained by two different factors. On the one hand, a reduction in rhizobial nodulation and nitrogenase activity has been reported under experimentally $\mathrm{N}$-enriched soils (Valladares et al., 2002), thus reducing growth among leguminous species (e.g. C. scopar- ius). The other possibility is that seedlings with higher growth rates demand greater $\mathrm{N}$ from the soil, and thus the low $\mathrm{N}$ availability in those plots would be a consequence and not the cause of seedling growth.

\section{Seedling survival}

Soil-water availability during summer was by far the most important direct factor determining seedling survival. Our SEM analysis corroborates therefore the role of summer drought as a major limiting factor for woody-seedling establishment in Mediterranean systems (Rey and Alcántara, 2000; Castro et al., 2005; Quero et al., 2008; Mendoza et al., 2009a,b), and for species of all successional stages. Although the survival of most species depended on water availability, $P$. sylvestris was the species with the strongest relationship, identifying it as the species with the highest water requirements from the set studied (Castro et al., 2005; Mendoza et al., 2009b). On the other hand, the two pioneer species C. scoparius and S. lavandulifolia were not affected by summer soil moisture, being the most resistant to drier conditions.

Overall, light did not strongly affect seedling survival, except for the two mid-successional shrubs B. hispanica and S. aria, where light reduced survival. Two different conclusions could be drawn from this result. First, survival is not limited by light in the shadiest plots, because deep shade is not part of the natural gradient of light variation in the study area ( $10 \%$ of full sunlight was the lowest value). Second, higher light availability in open plots did not increase mortality, at least in a direct way.

\section{Indirect and inter-stage effects}

Although direct effects were overall more important than indirect ones, in some cases the indirect influence of a factor (especially of light) was strong enough to change the sign of the total effect. For example, for Q. ilex emergence, the negative direct effect of light was offset by a stronger indirect positive effect. In the case of survival, despite that light directly affected tree-species survival in a positive way, it was partially cancelled by the negative indirect effect, especially in the case of $Q$. ilex and $P$. sylvestris, where the total effect was negative. These results highlight the importance of explicitly taking into account both direct and indirect effects of abiotic factors, since they may sometimes act in opposite ways.

Overall, there were no strong relationships among the successive processes involved in recruitment. In the case of deciduous trees, we found a relationship between emergence and survival, 
Table 3

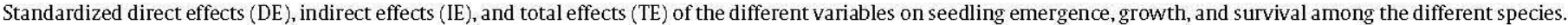
Significant direct effects are shown in bold type. Dashes indicate that relationships were not included in the model.

\begin{tabular}{|c|c|c|c|c|c|c|c|c|c|}
\hline & \multicolumn{3}{|c|}{ Emergence } & \multicolumn{3}{|c|}{ Growth } & \multicolumn{3}{|c|}{ Survival } \\
\hline & DE & IE & TE & DE & IE & TE & $\mathrm{DE}$ & IE & TE \\
\hline \multicolumn{10}{|l|}{ Q. ilex } \\
\hline Moist Spring & -0.37 & - & -0.37 & -0.21 & 0.04 & -0.17 & - & 0.06 & 0.06 \\
\hline Moist Summer & - & - & - & 0.24 & - & 0.24 & 0.46 & -0.05 & 0.41 \\
\hline Light & -0.07 & 0.23 & 0.16 & 0.55 & 0.03 & 0.58 & 0.03 & -0.28 & -0.25 \\
\hline Phosphorus & - & - & - & -0.07 & - & -0.07 & 0.01 & 0.01 & 0.02 \\
\hline Nitrogen & - & - & - & -0.04 & - & -0.04 & 0.06 & 0.01 & 0.07 \\
\hline Emergence & - & - & - & -0.11 & - & -0.11 & -0.06 & 0.02 & -0.04 \\
\hline Growth & - & - & - & - & - & - & -0.20 & - & -0.20 \\
\hline \multicolumn{10}{|l|}{ A.opalus } \\
\hline Moist Spring & 0.58 & - & 0.58 & -0.21 & 0.08 & -0.13 & - & -0.29 & -0.29 \\
\hline Moist Summer & - & - & - & 0.48 & - & 0.48 & 0.48 & 0.26 & 0.74 \\
\hline Light & -0.30 & -0.19 & -0.49 & 0.20 & 0.03 & 0.23 & 0.21 & -0.02 & 0.19 \\
\hline Phosphorus & - & - & - & -0.23 & - & -0.23 & 0.10 & -0.03 & 0.07 \\
\hline Nitrogen & - & - & - & -0.20 & - & -0.20 & -0.17 & -0.04 & -0.21 \\
\hline Emergence & - & - & - & 0.14 & - & 0.14 & -0.47 & 0.02 & -0.45 \\
\hline Growth & - & - & - & - & - & - & 0.12 & - & 0.12 \\
\hline \multicolumn{10}{|l|}{ P.sylvestris } \\
\hline Moist Spring & - & - & - & - & - & - & - & - & - \\
\hline Moist Summer & - & - & - & - & - & - & 0.57 & - & 0.57 \\
\hline Light & -0.32 & - & -0.32 & - & - & - & 0.15 & -0.22 & -0.07 \\
\hline Phosphorus & - & - & - & - & - & - & -0.13 & - & -0.13 \\
\hline Nitrogen & - & - & - & - & - & - & - & - & - \\
\hline Emergence & - & - & - & - & - & - & 0.19 & - & 0.19 \\
\hline Growth & - & - & - & - & - & - & - & - & - \\
\hline \multicolumn{10}{|l|}{ S.aria } \\
\hline Moist Spring & 0.06 & - & 0.06 & -0.06 & -0.01 & -0.07 & - & 0.01 & 0.01 \\
\hline Moist Summer & - & - & - & 0.42 & - & 0.42 & 0.30 & 0.09 & 0.39 \\
\hline Light & -0.74 & -0.03 & -0.77 & 0.19 & 0.15 & 0.34 & 0.20 & -0.24 & -0.04 \\
\hline Phosphorus & - & - & - & 0.31 & - & 0.31 & -0.29 & 0.17 & -0.12 \\
\hline Nitrogen & - & - & - & -0.02 & - & -0.02 & 0.05 & -0.01 & 0.04 \\
\hline Emergence & - & - & - & -0.22 & - & -0.22 & 0.37 & -0.05 & 0.32 \\
\hline Growth & - & - & - & - & - & - & 0.22 & - & 0.22 \\
\hline \multicolumn{10}{|l|}{ B.hispanica } \\
\hline Moist Spring & 0.01 & - & 0.01 & -0.31 & 0.01 & -0.30 & - & -0.08 & -0.08 \\
\hline Moist Summer & - & - & - & 0.44 & - & 0.44 & 0.36 & 0.11 & 0.47 \\
\hline Light & -0.24 & -0.01 & -0.25 & -0.03 & 0.04 & 0.01 & -0.32 & 0.06 & -0.26 \\
\hline Phosphorus & - & - & - & -0.13 & - & -0.13 & -0.04 & -0.03 & -0.07 \\
\hline Nitrogen & - & - & - & 0.08 & - & 0.08 & -0.04 & 0.02 & 0.02 \\
\hline Emergence & - & - & - & 0.09 & - & 0.09 & -0.22 & 0.02 & -0.20 \\
\hline Growth & - & - & - & - & - & - & 0.26 & - & 0.26 \\
\hline \multicolumn{10}{|l|}{ C.monogyna } \\
\hline Moist Spring & -0.13 & - & -0.13 & -0.25 & -0.01 & -0.26 & - & -0.09 & -0.09 \\
\hline Moist Summer & - & - & - & 0.41 & - & 0.41 & 0.30 & 0.16 & 0.46 \\
\hline Light & -0.20 & -0.06 & -0.26 & 0.52 & 0.06 & 0.58 & -0.32 & 0.19 & -0.13 \\
\hline Phosphorus & - & - & - & 0.17 & - & 0.17 & -0.14 & 0.05 & 0.09 \\
\hline Nitrogen & - & - & - & -0.04 & - & -0.04 & -0.14 & -0.02 & -0.16 \\
\hline Emergence & - & - & - & -0.02 & - & -0.02 & 0.06 & -0.01 & 0.05 \\
\hline Growth & - & - & - & - & - & - & 0.40 & - & 0.40 \\
\hline \multicolumn{10}{|l|}{ C.scoparius } \\
\hline Moist Spring & -0.04 & - & -0.04 & -0.01 & - & -0.01 & - & -0.01 & -0.01 \\
\hline Moist Summer & - & - & - & 0.22 & - & 0.22 & 0.17 & 0.03 & 0.20 \\
\hline Light & -0.39 & 0.02 & -0.37 & 0.61 & -0.07 & 0.54 & -0.17 & -0.02 & -0.19 \\
\hline Phosphorus & - & - & - & 0.09 & - & 0.09 & 0.12 & 0.01 & 0.13 \\
\hline Nitrogen & - & - & - & -0.21 & - & -0.21 & 0.08 & -0.03 & 0.06 \\
\hline Emergence & - & - & - & -0.01 & - & -0.01 & 0.09 & -0.01 & 0.08 \\
\hline Growth & - & - & - & - & - & - & 0.14 & - & 0.14 \\
\hline \multicolumn{10}{|l|}{ S.lavandulifolia } \\
\hline Moist Spring & 0.01 & - & 0.01 & -0.38 & -0.01 & -0.39 & - & -0.03 & -0.03 \\
\hline Moist Summer & - & - & - & 0.63 & - & 0.63 & 0.19 & 0.05 & 0.24 \\
\hline Light & 0.13 & -0.01 & 0.12 & 0.60 & -0.07 & 0.53 & 0.09 & -0.10 & -0.01 \\
\hline Phosphorus & - & - & - & 0.23 & - & 0.23 & 0.16 & -0.08 & 0.08 \\
\hline Nitrogen & - & - & - & -0.34 & - & -0.34 & -0.27 & -0.03 & -0.30 \\
\hline Emergence & - & - & - & -0.20 & - & -0.20 & -0.43 & -0.02 & -0.45 \\
\hline Growth & - & - & - & - & - & - & 0.09 & - & 0.09 \\
\hline
\end{tabular}

although with contrasting effects. This relation was positive for $S$. aria, indicating a consistent resource requirement during development and that the best places for emergence were also the best for growth. On the contrary, the negative relation for $A$. opalus indicates that the conditions favouring emergence reduced seedling survival, as a consequence of the changes in the ecological requirements during ontogeny described for this species (Quero et al., 2008). This pattern was also found for $S$. lavandulifolia. The positive relation- 
ship between growth and survival detected for mid-successional shrubby species suggest that seedlings with higher growth also have higher survival probabilities (Zavala et al., 2000; Zavala and Zea, 2004).

\section{Resource gradients and facilitation theory}

Besides the rising importance of facilitation as a topic in recent decades (Brooker et al., 2008), there are still gaps in knowledge on the facilitative interactions within the context of the ecological theory. Our results provide for the first time an integrated analysis for a wide set of species from different functional groups, showing that: (1) summer soil moisture strongly boosts survival; (2) light quantity does not directly reduce survival in any case; (3) light encourages the growth of all species; and (4) light has a negative effect on soil moisture. Therefore, soil moisture seems to be the key factor involved in the facilitation process, whereas the potential negative effect of light is indirectly mediated by a reduction in soil moisture. Most facilitation studies indicating a "microclimatic effect" (Maestre et al., 2003; Gốmez-Aparicio et al., 2004; Holzapfel et al., 2006) include in this term several co-occurring factors such as reduced light intensity, increased soil moisture, or greater soil fertility. By the use of SEM, we have separated the direct and indirect effect of these factors to show that the most important one is the direct effect of soil moisture. Thus, if water is not a limiting factor, plants are able to better grow with higher light availability. Our results therefore corroborate that the reduction of drought stress mediated by the nurse canopy is the main mechanism underlying facilitation in Mediterranean-type ecosystems (Gômez-Aparicio, 2008).

\section{Consequences under a climate-change scenario}

Whereas the main factors determining seedling emergence were species-specific (light for some species, spring water availability for others, or none of these factors for still others), summer soil moisture was a common resource for all species, with strong implications for growth and survival. This result supports the contention that, under global change, where summer drought is predicted to increase in Mediterranean areas (Houghton et al., 2001; Giorgi and Lionello, 2008), recruitment in this woody community could be seriously constrained by a reduction in both seedling growth and survival probability. Moreover, although all species in the community are prone to reduce their recruitment under drier conditions, our results suggest that not all of them would be affected with the same intensity. A gradient of water dependence is established in the community, identifying $P$. sylvestris as the most drought-intolerant species in terms of recruitment, followed by deciduous trees. This is not a surprising result, since $P$. sylvestris is at its southernmost distribution limit in this area (Castro et al., 2004; Mendoza et al., 2009b). On the contrary, pioneer shrubby species (as C. scoparius and S. lavandulifolia) are not affected by drier conditions, which together with the strong benefits of light on growth might allow the expansion of their populations to open areas and forest gaps with lower water availability. This alteration in recruitment probabilities of the species from the different functional groups may have far-reaching consequences for community structure and functioning. Lower recruitment of one of the dominant tree species might induce a shift in community dominance, favouring the expansion of the other more droughtresistant tree species (e.g. Q. ilex) or shrub species. These results strongly support the shrub-encroachment trends already reported for many Mediterranean ecosystems (Scarascia-Mugnozza et al., 2000; Acácio et al., 2009; Costa et al., 2010) due to the progressive loss of tree species having high water requirements.
Our experimental approach under field conditions, combined with robust analytical methods such as SEM, enabled us to identify the most important factors that could limit recruitment of this woody community, and how species-specific responses vary along resource gradients. The results discussed in this study represent another necessary step towards the development of a mechanistic model of Mediterranean woody-community dynamics that integrates species-specific responses for the different demographic stages involved in recruitment and that allow the prediction of ecological consequences of alterations in resource availability under a global-change scenario.

\section{Acknowledgements}

We thank the Consejería de Medio Ambiente (Andalusian Government) and the Direction of the Sierra Nevada National Park for facilities and support to carry out the experiment. We also thank Nacho Villegas, Ramôn Ruiz, and Susana Hitos for invaluable field and lab assistance, and three anonymous reviewers for their helpful comments. David Nesbitt improved English style of this manuscript. This study was supported by the coordinated Spanish MEC Project DINAMED (CGL2005-05830-C03) and GESBOME (P06RNM-1890), and by a grant FPI-MEC (BES-2006-13562) to L.M. This research is part of the GLOBIMED (www.globimed.net) network in forest ecology.

\section{References}

Acácio, V., Holmgren, M., Rego, F., Moreira, F., Mohren, G.M.J., 2009. Are drought and wildfires turning Mediterranean cork oak forests into persistent shrublands? Agroforest. Syst. 76, 389-400.

Arbuckle, J.L., 1994. AMOS: analysis of moment structures. Psychometrika 59, 135-137.

Bazzaz, F.A., Picket, S.T.A., 1980. Physiological ecology of tropical succession: a comparative review. Ann. Rev. Ecol. Evol. Syst. 11,287-310.

Bentler, P.M., Bonnet, D.G., 1980. Significance tests and goodness-of-fit in the analysis of covariance structures. Psychol. Bull. 88,588-606.

Blanco, E., Costa, M., Escribano, R., 2005. Los bosques ibéricos: una interpretación geobotánica. Planeta, Barcelona.

Bollen, K.A., 1989. Structural Equations With Latent Variables. John Wiley \& Sons, New York.

Brooker, R.W., Maestre, F.T., Callaway, R.M., Lortie, C.L., Cavieres, L.A., Kunstler, G., Liancourt, P., Tielbörger, K., Travis, J.M.J., Anthelme, F., Armas, C., Coll, L., Corcket, E., Delzon, S., Forey, E., Kikvidze,Z., Olofsson, J., Pugnaire, F., Quiroz, C.L., Saccone, P., Schiffers, K., Seifan, M., Touzard, B., Michalet, R., 2008. Facilitation in plant communities: the past, the present and the future. J. Ecol. 78, 1958-1965.

Browne, M.W., 1982. Covariance structures. In: Hawkins, D.M. (Ed.), Topics in Applied Multivariate Analysis. Cambridge University Press, Cambridge, pp. $72-141$.

Canadell, J., Zedler, P.H., 1995. Underground structures of woody plants in Mediterranean ecosystems of Australia, California and Chile. In: Arroyo, M.T.K., Zedler P.H., Fox, M.D. (Eds.), Ecology and Biogeography of Mediterranean Ecosystems in Chile, California and Aus tralia. Springer-Verlag, Berlin, pp. 177-210.

Carson, W.P., Pickett, S.T.A., 1990. Role of resources and disturbance in the organization of an old field plant community. Ecology 71, 226-238.

Castro, J., Zamora, R., Hódar, J.A., Gómez, J.M., 2004. Seedling establishment of a boreal tree (Pinus sylvestris) at its southernmost distribution limit: consequences of being in a marginal Mediterranean habitat. J. Ecol. 92, 266-277.

Cas tro, J., Zamora, R., Hódar, J.A., Gómez, J.M., 2005. Alleviation of summer drought boosts establishment success of Pinus sylvestris in a Mediterranean mountain an experimental approach. Plant Ecol. 181, 191-202.

Costa, A., Pereira, H., Madeira, M., 2010. Analysis of spatial patterns of oak decline in cork oak woodlands in Mediterranean conditions. Ann. For. Sci. 67 204p1-1204p.

Emborg, J., 1998. Understorey light conditions and regeneration with respect to the structural dynamics of a near-natural temperate deciduous forest in Denmark. For. Ecol. Manage. 106, 83-95.

Escudero, A., Iriondo, J.M., Olano, J.M., Rubio, A., Somolinos, R.C., 2000. Factors affecting establishment of a gypsophy te: the case of Lepidium subulatum (Brassicaceae). Am. J. Bot. 87, 861-871.

Flores, J.L.F., Jurado, E., 2003. Are nurse-protégé interactions more common among plants from arid environments? J. Veg. Sci. 14, 911-916.

García-Camacho, R., Iriondo, J.M., Escudero, A., 2010. Seedling dynamics at elevation limits: complex interactions beyond seed and microsite limitations. Am. J. Bot $17,1791-1797$ 
García-Fayos, P., Gulias, J., Martínez, J., Marzo, A., Melero, J.P., Traveset, A., Veintimilla, P., Verdû, M., Cerdán, V., Gasque, M., Medrano, H., 2001. Bases ecológicas para la recolección, almacenamiento y germinación de semillas de especies de uso forestal de la Comunidad Valenciana. Banc de Llavors Forestals, Valencia.

Garrido, J.L., Rey, P.J., Herrera, C.M., 2005. Pre- and post-germination determinants of spatial variation in recruitment in the perennial herb Helleborus foetidus L (Ranunculaceae). J. Ecol. 93,60-66.

Gaudio, N., Balandier, P., Marquier, A., 2008. Light-dependent development of two competitive species (Rubus idaeus, Cytisus scoparius) colonizing gaps in temperate forest. Ann. For. Sci. 65, 104p1-1104p.

Giorgi, F., Lionello, P., 2008. Climate change projections for the Mediterranean region. Global Planet. Change 63, 90-104.

Gómez, J.M., 2004. Importance of burial and microhabitat on Quercus ilex early recruitment: non-additive effects on multiple demographic processes. Plant Ecol. 172, 287-297.

Gômez-Aparicio, L., Zamora, R., Gómez, J.M., Hódar, J.A., Castro, J., Baraza, E., 2004 Applying plant facilitation to forest res toration in Mediterranean ecosystems: a meta-analysis of the use of shrubs as nurse plants. Ecol. Appl. 14, 1128-1138.

Gómez-Aparicio, L., Valladares, F., Zamora, R., 2006. Differential light responses of Mediterranean tree saplings: linking ecophysiology with regeneration niche in four co-occurring species. Tree Physiol. 26, 947-958.

Gómez-Aparicio, L., 2008. Spatial patterns of recruitment in Mediterranean plant species: linking the fate of seeds, seedlings and saplings in heterogeneous land scapes at different scales. J. Ecol. $96,1128-1140$.

Gómez-Aparicio, L., Pérez-Ramos, I.M., Mendoza, I., Matías, L., Quero, J.L., Castro, J. Zamora, R., Marañón, T., 2008. Oak seedling survival and growth along resource gradients in Mediterranean forests: implications for regeneration under current and future environmental scenarios. Oikos 117, 1683-1699.

Grubb, P.J., 1998. A reassessment of the strategies of plants which cope with shortages of resources. Persp. Plant Ecol. Evol. Syst. 1, 3-31.

Hampe, A., Arroyo, J., 2002. Recruitment and regeneration in populations of an endangered South Iberian Tertiary relict tree. Biol. Conserv. 107,236-271.

Harper, J.L., 1977. Population Biology of Plants. Academic Press, New York.

Hayduck, L.A., 1987. Structural Equation Modelling With LISREL: Essential and Advances. John Hopkins University Press, Baltimore.

Holzapfel, C., Tielbörger, K., Parag, H.A., Kigel, J., Sternberg, M., 2006. Annual plantshrub interactions along an aridity gradient. Basic Appl. Ecol. 7, 268-279.

Houghton, J.T., Ding, Y., Griggs, D.J., Noguer, M., van der Linden, P.J., Xiaosu, D., 2001 Climate change 2001: the scientific basis. Contribution of Working Group I to the Third Assessment Report of the Intergovernmental Panel on Climate Change (IPCC), Cambridge.

Houle, G., 1994. Spatiotemporal patterns in the components of regeneration of four sympatric tree spacies, Acer rubrum, A. sacchorum, Betula alleghaniensis and Fagus grandifolia. J. Ecol. 82, 39-53.

IPCC, 2007. Climate change, 2007. The Physical Science Basis: Working Group I Con tribution to the Fourth Assessment Report of the IPCC. Cambridge University Press, Cambridge.

Iriondo, J.M., Albert, M.J., Escudero,A., 2003. Structural equation modelling: an alternative for assessing causal relationships in threatened plant populations. Biol. Conserv. 113, 367-377.

Jensen, K.D., Beier, C., Michelsen, A., Eemmett, B.A., 2003. Effects of experimental drought on microbial processes in two temperate heathlands at contrasting water conditions. Appl. Soil Ecol. 24, 165-176.

Jonasson, S., Michelsen, A., Schmidt, I.K., Nielsen, E.V., 1999. Responses in microbes and plants to changed temperature, nutrient, and light regimes in the arctic. Ecology 80,1828-1843.

Jordano, P.. Herrera, C.M., 1995. Shuffling the offspring: uncoupling and spatial discordante of multiple stages in vertebrate seed dispersal. Ecoscience 2,230-237.

Jurado, E., García, J.F., Flores, J., Estrada, E., 2006. Leguminous seedling establishment in Tamaulipan thornscrub of northeastern Mexico. For. Ecol. Manage. 221 $133-139$.

Kitajima, K., 1994. Relative importance of photosynthetic rates and allocation patterns as correlates of seedling shade tolerance of 13 tropical trees. Oecologia 98 $419-428$.

Kitajima, K., Fenner, M., 2000. Ecology of seedling regeneration. In: Fenner, M. (Ed.) Seeds: The Ecology of Regeneration in Plant Communities. CAB Int.,pp. 331-359.

Laskurain, N.A., Escudero, A., Olano, J.M., Loidi, J., 2004. Seedling dynamics of shrubs in a fully closed temperate forest: greater than expected. Ecography 27 $650-658$.

Lloret,F., Casanovas, C., Peñuelas, J., 1999. Seedling survival of Mediterranean shrubland species in relation to root:shoot ratio, seed size and water and nitrogen use. Funct. Ecol. 13, 210-216

Lohelin, J.C., 1992. Latent Variable Models. An Introduction to Factor, Path, and Structural Analysis. Lawrence Erlbaum, Hillsdale

Luzuriaga, A.L., Escudero, A., 2008. What determines emergence and netrecruitment in an early succession plant community? Dis entangling biotic and abioticeffects. J. Veg. Sci. $19,445-456$

Maestre, F.T., Bautista, S., Cortina, J., 2003. Positive, negative, and net effects in grass-shrub interactions in Mediterranean semiarid grasslands. Ecology 84 3186-3197.
Matías, L., Castro, J., Zamora, R., 2011. Soil-nutrient availability under a global change scenario in a Mediterranean mountain ecosystem. Global Change Biol. $17,1646-1657$.

McNickle, G.G., St.Clair, C.C., Cahill, J.F., 2009. Focusing the metaphor: plant root foraging behaviour. Trends Ecol. Evol. 24, 419-426.

Mendoza, I., Gómez-Aparicio, L., Zamora, R., Matías,L., 2009a. Recruitment limitation in forest communities in a degraded Mediterranean landscape. J. Veg. Sci. 20, $367-376$.

Mendoza, I., Zamora, R., Castro, J., 2009b. A seeding experiment for testing treecommunity recruitment under variable environments: implication for forest regeneration and conservation in Mediterranean habitats. Biol. Conserv. 142, 1491-1499.

Mitchell, R.J., 1992. Tes ting evolutionary and ecological hypotheses using path analys is and structural equation modeling. Funct. Ecol. 6, 123-129.

Mulaik, S.A., James, L.R., Van Alstine, J., Bennet, N., Lind, S., Stilwell, C.D., 1989. evaluation of goodness-of-fit indices for structural equation models. Psychol. Bull. $105,430-445$

Peñuelas, J., Boada, M., 2003. A global-change induced biome shift in the Montseny mountains (NE Spain). Global Change Biol. 9, 131-140.

Pérez-Ramos, I.M., Marañón, T., 2009. Effects of waterlogging on seed germination of three Mediterranean oak species: ecological implications. Acta Oecol. $35,422-428$.

Quero, J.L., Villar, R., Marañón, T., Zamora, R., Poorter, L., 2007. Seed mass effect in four Mediterranean Quercus species (Fagaceae) growing in contrasting light environments. Am. J. Bot. 94, 1795-1803.

Quero, J.L., Gómez-Aparicio, L., Zamora, R., Maestre, F.T., 2008. Shifts in the regeneration niche of an endangered tree (Acer opalus ssp. granatense) during ontogeny: using an ecological concept for application. Basic Appl. Ecol. 9, 635-644.

Quero, J.L., Herrero, A., Zamora, R., 2011. Spatial and temporal variation of woody plant survival: implications for management. Basic Appl. Ecol. 12, 161-171.

Rey, P.J., Alcántara, J.M., 2000. Recruitment dynamics of a fleshy-fruited plant (Olea europaea): connecting patterns of seed dispersal to seedling establishment. J. Ecol. 88, 622-633.

Sardans, J., Peñuelas, J., 2007. Drought changes phosphorus and potassium accumulation patterns in an evergreen Mediterranean forest Funct. Ecol. 21, 191-201.

Sardans, J., Rodá, F., Peñuelas, J., 2004. Phosphorus limitation and competitive capacities of Pinus halepensis and Quercus ilex subsp. rotundifolia on different soils. Plant Ecol. 174,305-317.

Scarascia-Mugnozza, G., Oswald, H., Piussi, P., 2000. Forests of the Mediterranean region: gaps in knowledge and research needs. For. Ecol. Manage. 132,97-109.

Schreeg, L., Kobe, R.K., Walters, M.B., 2005. Tree seedling growth, survival and morphology in response to landscape-level variation in soil resource availability in northern Michigan. Can. J. For. Res. 35, 263-273.

Shipley, B., 2000. Cause and Correlation in Biology: A User's guide to Path Analysis, Structural Equations, and Causal Inference. Cambridge University Press, Cambridge.

Stevens, M.H.H., Shirk, R., Steiner, C.E., 2006. Water and fertilizer have opposite effects on plant species richness in a mesic early successional habitat. Plant Ecol. 183, 27-34.

Tanaka, J.S., 1987. How big is enough? sample size and goodness of fit in structural equation models with latent variables. Child Dev. 58, 134-146.

Tanaka, J.S., Huba, G.J., 1985. A fit index for covariance structure models under arbitrary GLS estimation. Brit J. Math. Stat. Psychol. 38, 197-201.

Valladares, F., 2000. Características mediterráneas de la conversión fotosintética de luz en biomasa: de órgano a organismo. In: Zamora, R., Pugnaire, F.I. (Eds.), Ecosistemas mediterráneos. Análisis funcional. CSIC-AEET, Madrid, pp. 67-93.

Valladares, F., Guzmán, B., 2006. Canopy structure and spatial heterogeneity of understory light in abandoned Holm oak woodland. Ann. For. Sci. 63, 749-761.

Valladares, F., Pearcy, R.W., 1997. Interactions between water stress, sun-shade acclimation, heat tolerance and photoinhibition in the sclerophyll Heteromeles arbutifolia. Plant Cell Environ. 20, 25-36.

Valladares, F., Pearcy, R.W., 1998. The functional ecology of shoot architecture in sun and shade plants of Heteromeles arbutifolia M Roem., a Californian chaparral shrub. Oecologia 121, 171-182.

Valladares, F., Villar-Salvador, P., Domínguez, S., Fernández-Pascual, M., Peñuelas, J.L., Pugnaire, F.I., 2002. Enhancing the early performance of the leguminous shrub Retamasphaerocarpa(L.) Boiss.: fertilisation versus Rhizobium inoculation. Plant Soil 240,253-262.

Watanabe, S., Olsen, R.S., 1965. Test of an ascorbic acid method for determining phosphorus in water and $\mathrm{NaHCO}_{3}$ extracts from soil. Soil Sci. Soc. Am. Process. $29,677-678$

Yahdjian, L, Sala, O., 2002. A rainout shelter design for intercepting different amounts of rainfall. Oecologia 133, 95-101.

Zar, J.H., 1984. Biostatistical Analysis, 2nd ed. Prentice-Hall, London.

Zavala, M.A., Espelta, J.M., Retana, J., 2000. Constraints and trade-offs in Mediterranean plant communities: the case of Holm Oak-Aleppo pine forests. Bot Rev. $66,119-149$.

Zavala,M.A.,Zea, G.E., 2004. Mechanisms maintaining biodiversity in Mediterranean pine-oak forests: insights from a spatial simulation model. Plant Ecol. 171, $197-207$. 